\title{
Pesquisa da qualidade de vida do profissional farmacêutico de rede de drogarias
}

\author{
Survey on the quality of life of pharmaceutical professionals of drugstore \\ Investigación sobre la calidad de vida de los profesionales farmacéuticos de cadena de farmacias
}

Recebido: 04/04/2021 | Revisado: 12/04/2021 | Aceito: 07/05/2021 | Publicado: 21/05/2021

\author{
Suiane dos Santos Fialho De Lima \\ ORCID: https://orcid.org/0000-0001-7596-9420 \\ Universidade Federal do Pará, Brasil \\ E-mail: suianefialholima@hotmail.com \\ Maria Fâni Dolabela \\ ORCID: https://orcid.org/0000-0003-0804-5804 \\ Universidade Federal do Pará, Brasil \\ E-mail: fani@ufpa.br; fanidolabela20@gmail.com
}

\begin{abstract}
Resumo
Objetivo: O presente estudo teve como objetivo avaliar a qualidade de vida entre farmacêuticos, em especial de rede de drogarias. Metodologia: O instrumento adaptado foi de WHOQOL, sendo utilizado 5 domínios (biológicos, psicológicos, nível de independência, relações sociais e trabalho-moradia), sendo estabelecido scores para os domínios e para a qualidade de vida. Foram incluídos no estudo 21 farmacêuticos de ambos os gêneros, de várias idades e tempo de profissão, que trabalhassem em uma drogaria de rede nas funções de gerentes farmacêuticos (GF) e responsável técnico (RT). Resultados: Houve predomínio de mulheres, RT, entre 20-40 anos, que na maioria dos domínios foram classificas como bom a muito bom. Entretanto, no domínio III (nível de independência), 20 farmacêuticos demonstraram reduzido nível e tiveram uma nota inferior a 5 e apenas 1 a nota foi 5 . Para os demais domínios, os números de farmacêutico com nota inferior a 5,0 (classificado como ruim) foram: DI biológico- 4, DII psicológico-2; DIV relações sociais-4 e DV trabalho moradia- 2. Entretanto, devido as baixas pontuações em DIII, 8 farmacêuticos foram classificados como baixa qualidade de vida. Percebeu-se também que o instrumento permite rastrear alguns problemas de saúde, de relacionamento, problemas trabalhistas, além da avaliação da qualidade de vida. Conclusão Apesar do número reduzido de participantes, os resultados não devem ser desconsiderados. Eles podem indicar que muitos farmacêuticos possam estar enfrentados sérios problemas de saúde, relacionamentos e no trabalho. Neste contexto, é importante que novos estudos sejam realizados para a avaliação da qualidade de vida e o rastreio dos possíveis problemas enfrentados pela classe.
\end{abstract}

Palavras-chave: Farmacêuticos; Drogarias; Qualidade de vida.

\begin{abstract}
Objective: This study has the objective of assessing the quality of life among pharmacists, especially in the drug network. Methodology: Or instrument adapted from WHOQOL, using 5 domains (biological, psychological, level of independence, social relations and work-life), establishing scores for the domains and for the quality of life. Included in the list are not 21 pharmacists of both genders, of varying degrees and time of skill, who work in a drug store from network functions of Pharmaceutical Managers (GF) and Technical Responsible (RT). Results: There was a predominance of women, RT, between 20-40 years old, who had more than two domains for which they were classified as good to very good. In the meantime, no domain III (level of independence), 20 pharmacists demonstrated a reduced level and scored less than 5 and only 1 st note was 5 . For the other domains, the pharmacist numbers with a note lower than 5.0 (classified as bad) was: biological ID-4, psychological ID-2; DIV social relationships-4 e DV housing work- 2. Meanwhile, due to the low scores on DIII, 8 pharmaceutics were classified as low quality of life. It was realized also that the instrument allows to track some health problems, relationships, labor problems, as well as an endorsement of the quality of life. Conclusion Despite the small number of participants, the results should not be disregarded. They can indicate that many pharmaceuticals may be facing serious problems of health, relationships and non-work. In this context, it is important that new studies are carried out to assess the quality of life and trace two possible problems faced in the class.
\end{abstract}

Keywords: Pharmacists; Drugstores; Quality of life.

\section{Resumen}

Objetivo: El presente estudio tuvo como objetivo evaluar la calidad de vida de los farmacéuticos, especialmente de las cadenas de farmacias. Metodología: El instrumento adaptado fue del WHOQOL, utilizando 5 dominios (biológico, psicológico, nivel de independencia, relaciones sociales y trabajo-vivienda), estableciéndose puntajes para los dominios y para la calidad de vida. El estudio incluyó a 21 farmacéuticos de ambos géneros, de distintas edades y periodos en la profesión, que trabajaban en una cadena de farmacias en los roles de gerentes farmacéuticos (FG) y 
gerente técnico (RT). Resultados: hubo predominio de mujeres, RT, de 20 a 40 años, que en la mayoría de los dominios se clasificaron de buenas a muy buenas. Sin embargo, en el dominio III (nivel de independencia), 20 farmacéuticos mostraron un nivel bajo y tuvieron una puntuación por debajo de 5 y solo 1 fue una puntuación de 5 . Para los otros dominios, el número de farmacéuticos con una puntuación por debajo de 5,0 (clasificados como malos) fueron: biológico ID-4, psicológico ID-2; Relaciones sociales DIV-4 y DV trabajo-vivienda- 2. Sin embargo, debido a los bajos puntajes en DIII, 8 farmacéuticos fueron clasificados como de baja calidad de vida. También se notó que el instrumento permite rastrear algunos problemas de salud, parentescos y laborales, además de evaluar la calidad de vida. Conclusión A pesar del pequeño número de participantes, los resultados no deben ignorarse. Pueden indicar que muchos farmacéuticos pueden estar enfrentando problemas graves de salud, relaciones y trabajo. En este contexto, es importante que se realicen nuevos estudios para evaluar la calidad de vida y rastrear los posibles problemas que enfrenta la clase.

Palabras clave: Farmacéuticos; Farmacias; Calidad de vida.

\section{Introdução}

A satisfação no trabalho é um fenômeno complexo influenciado por uma série de fatores, alguns relacionados as atividades laborais como aspirações por cargo mais elevados e tristeza em virtude de problemas de convívio com colegas de trabalho ou frustrações pela baixa remuneração e outros fatores como a felicidade individual, afetando, em última instância, as atitudes em relação a si mesmo, à família e à organização onde trabalha (Ferreira \& Anderson, 2020).

Existe uma associação negativa entre satisfação no trabalho e sobrecarga de trabalho (Assis, 2019), associada a más condições de trabalho que pode, muitas vezes, levar à exaustão física e mental, afetando a produtividade, desempenho, absenteísmo, rotatividade, comportamento de cidadania organizacional, saúde e bem-estar, satisfação com a vida e satisfação do paciente com o serviço recebido (Santana \& Servo, 2019).

São vários os impactos da sobrecarga de trabalho na saúde do trabalhador e na qualidade de vida do mesmo, podendo ressaltar o esgotamento emocional, a insatisfação na realização da atividade, à qualidade de vida no trabalho sobre a satisfação laboral e conflito de trabalho-família. Acrescenta-se que a fadiga incessante, a falta de perspectivas, a frustração, a ansiedade, a depressão, o medo, a desmotivação com o trabalho e a sobrecarga de tarefas são prejudiciais aos profissionais da saúde, influenciando negativamente no comportamento dos mesmos (Fagundes, Costa \& Moreira, 2017; Neves, Campos \& Morais, 2020).

O impacto da profissão na saúde e qualidade de vida dos farmacêuticos tem sido pouco estudado. Um estudo realizado com 1.737 farmacêuticos em atividade nos Estados Unidos, relatou que 68\% dos profissionais apresentavam quadro de estresse no trabalho e sobrecarga de funções, sendo que isso impactou na vida pessoal de uma parte significativa (32\%). Os entrevistados ainda relataram sentimento de incapacidade de fornecer serviços farmacêuticos qualificados, devido ao excesso de tarefas administrativas que precisam ser priorizadas (Mott, Doucette, Gaither, Pedersen \& Schommer, 2004).

Além da jornada extensa de trabalho, outros fatores impactam na saúde física e mental dos farmacêuticos, tais como: número insuficiente de profissionais no ambiente laboral, diversas interrupções durante a execução da tarefa para atender outras demandas (Vilela, Soares, Gusmão, Torres \& Sá, 2015); não ter perspectiva de crescimento na empresa; trabalho repetitivo; baixo salário; exercer funções adversas às suas atribuições (Johnson, O'Connor, Jacobs, Hassell. \& Ashcroft, 2014; Phipps, Malley \& Ashcroft, 2012); entre outros problemas.

Apesar dos inúmeros problemas que os farmacêuticos enfrentam em sua rotina labora, como os citados anteriormente, ainda são escassos os estudos que avaliaram o impacto. Do trabalho na qualidade de vida e saúde desses profissionais. Pela ausência na literatura de qualquer pesquisa que analise a temática, o pressente estudo teve por objetivo avaliar a qualidade de vida dos farmacêuticos, em especial, que trabalham em redes de drogarias. 


\section{Metodologia}

Trata-se de um estudo de caráter prospectivo, descritivo e qualitativo, com profissionais farmacêuticos que atuam em drogarias (Pereira, et al., 2018). O estudo desenvolve-se por meio de um questionário eletrônico que foi elaborado no GoogleForms para os responsáveis técnicos (RT) e gerentes farmacêuticos (GF), sendo enviados por WhatsApp ou e-mail convites e se aceitavam foi encaminhado o link do questionário (Quadro 1).

Como critérios de inclusão foram adotados: farmacêuticos registrados no Conselho Regional de Farmácia do Pará (CRF PA) que trabalham em redes de farmácias ou drogarias que possuem unidades no Município de Belém. Os critérios de exclusão não formam incluídos os profissionais que não trabalham em redes de farmácias ou drogarias que não concordar com o Termo de Consentimento Livre e Esclarecido (TCLE).

\subsection{Adequação do instrumento}

Inicialmente, foi realizado um estudo do método de WHOQOL que consiste em cem perguntas referentes a seis domínios: físico, psicológico, nível de independência, relações sociais, meio ambiente e espiritualidade/religiosidade/crenças pessoais. (Fleck, 2000). Após ampla análise, foram mantidos 5 domínios (D) e alguns nomes foram adaptados: DI- biológico ao invés físico; DII- psicológico; DIII- nível de independência; DIV- relações sociais; DV - trabalho e moradia ao invés de meio ambiente.

Em síntese, as seguintes questões foram avaliadas em cada domínios: domínio I- biológico (saúde, sono e energia); domínio II- psicológico (autoavaliação a qualidade de vida, sentido da vida; capacidade de concentração; segurança na tomada de decisão, aparência pessoal); domínio III- nível de independência (mudanças administrativas promovidas pelos Gfs e nas relações interpessoais); domínio IV- relações sociais (relações pessoais; trabalho colaborativo - apoio; impacto do trabalho na vida pessoal; atividade sexual); domínio V- trabalho e moradia (satisfação salarial; jornada de trabalho; distancia casatrabalho-casa; condição de moradia; lazer; férias; possibilidade de capacitação; informações suficientes para realizar o trabalho) (Tabela 1). Também, foi introduzido a avaliação de cada domínio de forma individualizada e sua estratificação em ruim até ótimo (média: < 5,0 ruim; 5,0 até 6,9- bom; 7,0 até 8,9- muito bom; $\geq 9,0$ ótimo). Desta forma, pode-se observar em quais domínios encontram-se os maiores problemas.

Por último, adotou-se um score que permite inferir em relação a qualidade de vida dos farmacêuticos. Após o preenchimento da tabela 1, para cada farmacêutico, foram somadas as notas e divididas pelo número de itens, chegando à média. Ao final, foi realizado a média dos domínios e feito a estratificação da qualidade de vida de cada profissional: média $\leq$ 5,0 baixa qualidade de vida; entre 5,1-8,0 qualidade de vida mediana; > 8,1- boa qualidade de vida. 
Tabela 1 - Adaptação de WHOQOL-100.

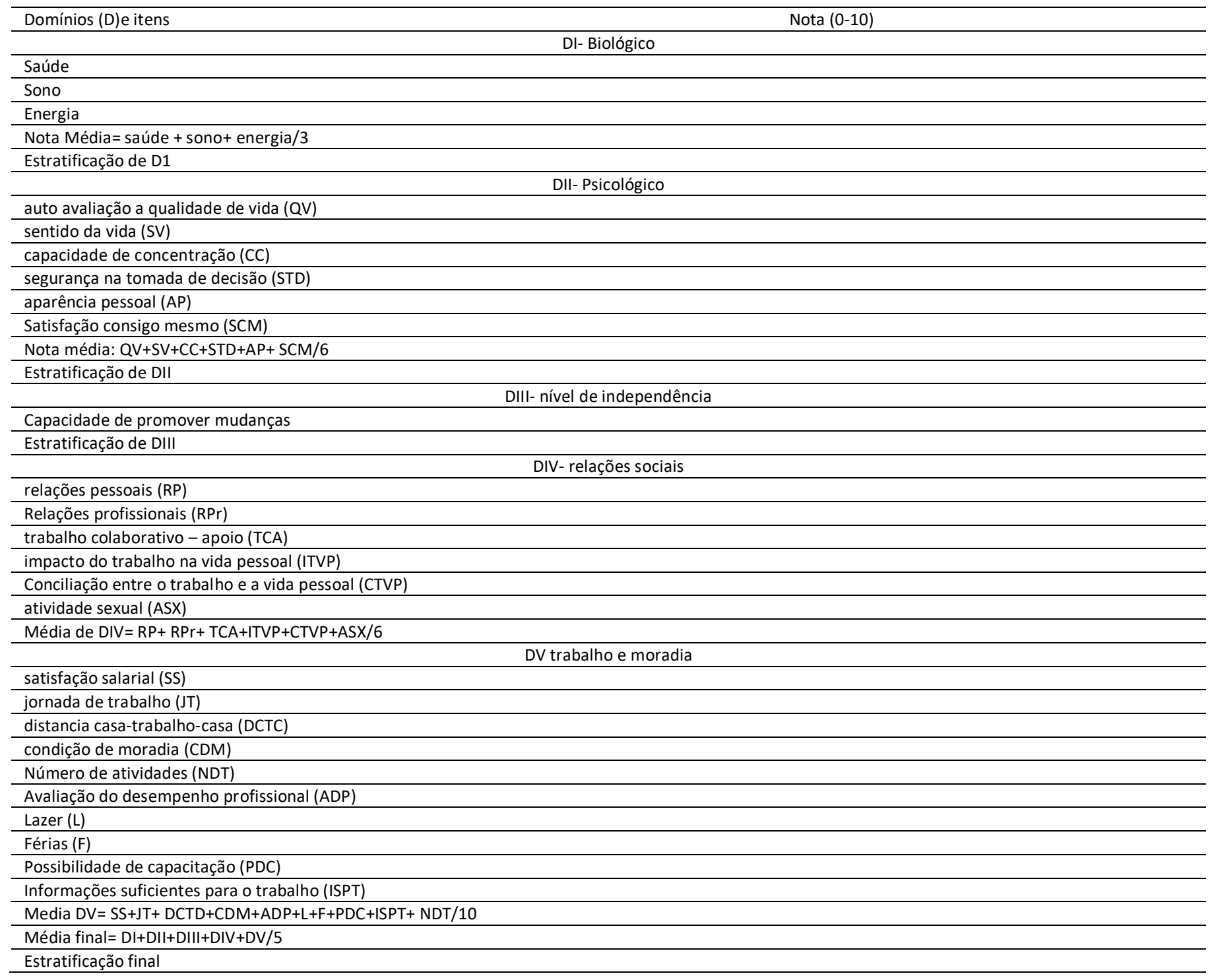

Legenda: notas de 0-10, média $\leq 5,0$ baixa qualidade de vida; entre 5,1-8,0 qualidade de vida mediana; > 8,1- boa qualidade de vida. Fonte: Adaptado de Fleck (2000).

Os farmacêuticos foram convidados através de mídias digitais e receberam um texto explicando os objetivos da pesquisa, benefícios e esclarecidos que não havia riscos. Todos os farmacêuticos que aceitaram, assinaram de modo digital o TCLE e responderam às perguntas na plataforma GoogleForms. O período de entrevista foi de abril a agosto de 2020.

Utilizou-se para coleta de dados uma planilha de banco de dados formulado pelos pesquisadores, levando-se em conta as variáveis contidas no questionário do farmacêutico gerente e farmacêuticos quanto a estrutura administrativa, qualidade de vida, serviços farmacêuticos, recursos humanos, financeiro e para o farmacêutico não gerente as variáveis referentes a sua rotina de trabalho, importância da presença no balcão e ausência do farmacêutico. Os dados foram armazenados em um banco de dados do software Microsoft Office Excel e tabulados a partir dos resultados.

Este trabalho foi submetido à Plataforma Brasil de acordo com a Resolução n 466, de 12 de dezembro de 2012, que regulamenta as diretrizes e normas de pesquisas envolvendo seres humanos (BRASIL, 2012) com parecer consubstanciado favorável do comitê de ética da Universidade Federal do Pará, tendo como Parecer 3.780.348 e CAAE no 26849219.2.0000.0018, de 18 de dezembro de 2019 e emenda no dia 13 de março de 2020. 
Quadro 1 - Questionário utilizado para a entrevista.

\begin{abstract}
Algumas informações importantes: 1-Cargo: ( ) Gerente farmacêutico ( )Responsável técnica; 2-faixa etária ( )20-30 anos; ( ) >30-40 anos; ( ) >40-50 anos; ( )> 50- 60 anos; ( )> 60 anos; 3-Tempo de profissão( ) menos de 5 anos; ( ) de 5 a 10 anos; () de 10 a 15 anos; ( ) Mais de 15 anos; 4 - existe outro farmacêutico no horário de seu trabalho: ( ) sim; ( ) não; 5- nível de satisfação com acesso aos serviços de saúde: ( ) Muito insatisfeito; ( ) Insatisfeito: ( ) Moderadamente satisfeito; ( ) Satisfeito; ( ) Muito satisfeito; 6- Pontos positivos de cargo; 7- Pontos negativos do cargo; 8-0 que você mudaria no serviço?
\end{abstract}

Domínio I- Biológico: 1-Em relação ao sono: ( ) Tenho insônia frequentemente (0 a 2 pontos); ( ) Raramente, eu tenho insônia (3 a 4 pontos); ( ) Durmo pouco, as vezes, acordo cansada (5 a 6 pontos); ( ) Quase sempre, eu durmo bem (7-9 pontos); ( )- Durmo muito bem (10 pontos); 2 -Você tem energia suficiente para seu dia-a- dia? ( ) Nunca tenho energia (0); ( ) Raramente tenho energia ( 2 a 4 pontos); ( ) Às vezes, eu tenho energia (5 a 6 pontos); () Na maioria das vezes, eu tenho energia (7-8 pontos); ( ) Sempre tenho energia (9-10pontos); 3- Em relação a sua saúde: ( )Estou muito insatisfeito com minha saúde, pois não tenho tempo para realizar os cuidados que preciso ( 0 a 1ponto); ( ) Estou insatisfeito ( 2 a 4 pontos); ( ) Nem satisfeito e nem insatisfeito ( 5 a 6 pontos); ( ) Acho que tenho cuidado bem de minha saúde, porém, ainda posso melhorar ( 7 a 9 pontos); ( ) Muito satisfeito (10 pontos)

Domínio II- Psicológico: 1- Como você avalia sua qualidade de vida? ( )Muito ruim (0); ( )Ruim (1 a 4 pontos); ( )Normal, isto é, nem ruim e nem boa (5 a 6 pontos); ( )Boa (7 a 9 pontos); ( )Muito boa (10 pontos); 2 - Em que medida você acha que a sua vida tem sentido? ( )Não faz sentido (0); ( )Às vezes, eu encontro algum sentido ( 1 a 4 pontos); ( )Muitos momentos, penso que minha vida faz sentido, entretanto, em outros momentos não vejo nenhum sentido ( 5 a 6 pontos); ( Quase sempre, minha vida sentido ( 7 a 8 pontos); ( Sempre faz sentido ( 9 a 10 pontos); 3-O quanto você consegue se concentrar durante as atividades? ( )Nada (0 a 1 ponto); ( )Muito pouco ( 2 a 4pontos); ( )Pouco(5 a 6 pontos); ( )Bastante (7 a 8 pontos); ( )Extremamente (9 a 10 pontos); 4- Nas suas tomadas de decisão ou durante as atividades profissionais, você se sente seguro? ( )Nunca (0 a 1 ); ( Raramente, eu me sinto seguro ( 2 a 4pontos); ( )Alterno, em alguns momentos sou seguro, outros sinto insegurança (5 a 6 pontos); ( )Na maioria das vezes, sou seguro (7 a 8 pontos); ( )Sempre sou seguro( 9 a 10 pontos); 5 - Em que extensão, o trabalho interfere negativamente em sua aparência? ( )Extremamente ( 0 a 1 ponto); ( )Muito ( 2 a 4 pontos); ( )Moderadamente (5 a 6 pontos); ( )Muito pouco (7 a 8 pontos); ( ) Na da ( 9 a 10 pontos); 6 Qual o seu grau de satisfação consigo mesmo: Muito insatisfeito ( 0 a 1 ponto); Insatisfeito ( 2 a 4 pont os); Moderadamente satisfeito (5 a 6 pontos); Satisfeito(7 a 8 pontos); Extremamente satisfeito(9 a 10 pontos).

Domínio III- nível de independência- Depois que você assumiu a gerencia, você conseguiu fazer alguma alteração na parte administrativa de sua loja? Se sim: quais foram as mudanças? Se não: Você não tem autonomia pra realizar mudanças? Somente para gerentes farmacêuticos: Depois que assumiu a gerencia, houve melhoria nas relações interpessoais? Se sim, quais foram as melhorias? (mudanças no serviço > 5 pontos; apenas melhorias no serviço< 5; deve-se considerar o impacto para o serviço e profissionais; nenhuma alteração e relata apenas cumprir as normas estabelecidas=0) Domínio IV- relações sociais: 1-Qual o seu grau de satisfação com suas relações pessoais (familiares, amigos e conhecidos); ( ) Muito insatisfeito (0 a 1 ponto); ( )Insatisfeito (2 a 4 pontos); ( ) Moderadamente satisfeito ( 5 a 6 pontos); ( ) Satisfeito (7 a 8 pontos);( )Extremamente satisfeito (9-10 pontos);2-Qual o seu grau de satisfação com suas relações profissionais? ( ) Muito insatisfeito (0 a 1 ponto); ( )Insatisfeito (2 a 4 pontos); ( )Moderadamente satisfeito ( 5 a 6 pontos); ( Satisfeito (7 a 8 pontos); ( ) Extremamente satisfeito (9-10 pontos); 3-Para desenvolver as atividades profissionais, você recebe dos outros o apoio de que necessita? ( )Nunca recebo apoio (0 a 1 ponto); ( )Raramente recebo apoi o (2 a 4 pontos); ( )Às vezes, recebo o apoio dos demais profissionais ( 5 a 6 pontos); ( ) Na maioria das vezes, recebo o apoio dos demais profissionais ( 7 a 8 pontos); ( ) Sempre posso contar com minha equipe (9 a 10 pontos); 4- Em que medida, o exercício profissional interfere na sua vida particular? ( ) Nada ( 9 a 10 pontos); ( )Muito pouco(7 a 8 pontos); ( )Mais ou menos (5 a 6 pontos); ( )Bastante ( 2 a 4 pontos); ( )Extremamente (0 a 1 ponto); 5 -Você consegue conciliar sua vida profissional, com a vida familiar e outras atividades? ( )Não consigo (0 a 1 ponto); ( )Raramente, eu consigo conciliar ( 2 a 4 pontos); Às vezes, eu consigo conciliar ( 5 a 6 pontos); ( )Na maioria das vezes, eu consigo conciliar ( 7 a 8 pontos); ( )Sempre, eu consigo conciliar ( 9 a 10pontos); 6-Qual o grau de satisfação com sua vida sexual (1 muito insatisfeito- 0 a 1 ponto.... 5 muito satisfeito- 9 a 10 pontos)

Domínio V- trabalho e moradia: 1-Qual o nível de satisfação salarial: ( )completamente insatisfeito (0 a 1ponto); ( )Insatisfeito (2 a 4 pontos); ( )Nem insatisfeito, nem satisfeito ( 5 a 6 pontos); ( Satisfeito ( 7 a 8 pontos); ( )Muito satisfeito (9 a 10 pontos); 2 - Em relação a sua jornada de trabalho, você acha? ( )A carga horária é muito superior ao preconizado pela classe ( 0 a 1ponto); ( )A carga horária é superior ao preconiza do pela classe ( 2 a 4 pontos); ( )A carga horária é a preconizada pela classe, porém frequentemente faço hora extra sem remuneração (5 a 6 pontos); ( )A carga horária é a preconizada pela classe, porém frequentemente faço hora extra com remuneração ( 7 a 8 pontos); ( )Adequada 99 a 10 pontos); 3 - Em relação ao tempo entre sua moradia e trabalho: ( )Gasto mais de $4 \mathrm{~h} /$ dia para chegar ao trabalho e retornar para casa ( 0 a 1 ponto); ( )Gasto entre 2 a $4 \mathrm{~h} /$ dia para chegar ao trabalho e retornar para casa ( 2 a 4 pontos); ( )Gasto entre 1 a 2 horas para chegar ao trabalho e retornar para casa ( 5 a6 pontos); ( )Gasto até 1 hora para chegar ao trabalho (7 a 8 pontos); ( )Moro próximo ao trabalho ( 9 a 10 pontos); 4- Em relação a sua condição de moradia, qual o seu nível de satisfação? ( )completamente insatisfeito ( 0 a 1ponto); ( )Ins atisfeito (2 a 4 pontos); ( )Nem insatisfeito, nem satisfeito (5 a 6 pontos); ( )Satisfeito ( 7 a 8 pontos); ( )Muito satisfeito ( 9 a 10 pontos); 5 -Em relação ao número de atividades desenvolvidas diariamente: ( )Excesso de diferentes atividades, sendo que algumas atribuições não tem relação ao cargo(0 a 1ponto); ( )Muitas atividades diferentes, sendo que algumas atribuições não tem relação ao cargo (3 a 4 pontos); ( )Algumas atividades não estão relacionadas ao cargo, porém o número é compatível com a jornada de trabalho(5 a 6 pontos); ( )Muitas atividades diárias relacionadas ao cargo (7 a 8 pontos); ( )adequadas (9 a 10 pontos); 6-Como você classifica o seu desempenho nas atividades do seu dia-a-dia: ( )completamente insatisfeito ( 0 a 1ponto); ( )Insatisfeito ( 2 a 4 pontos); ( )Nem insatisfeito, nem satisfeito ( 5 a 6 pontos); ( )Satisfeito ( 7 a 8 pontos); ( )Muito satisfeito ( 9 a 10 pontos); 7-Com que frequência você tem atividades de lazer? ( )Nunca (0 a 1 ponto); ( )1 vez ao mês ( 2 a 4 pontos); ( 2 vezes ao mês (5 a 6 pontos); ( ) Semanalmente(7 a 8 pontos); ( Diariamente (9 a 10 pontos); 8 - Durante as férias, você: ( )Aproveita para trabalhar em alguma outra atividade ( 0 a 1 ponto); ( )Vende até 10 dias para a empresa ( 2 a 4 pontos); ( )Alterna momentos de trabalho com lazer (5 a 6 pontos); ( )Procura, na maioria do tempo, descansar ( 1 a 8 pontos); ( )Dedica, todo o tempo, ao descanso, lazer, viagem e/ ou outras atividades (9 a 10 pontos); 9 - Com qual frequência, você teve oportunidade de se capacitar: ( )Nunca 90 a 1 ponto); ( ) Raramente ( 2 a 4 pontos); ( )No máximo 1 vez ao ano ( 5 a 6 pontos); ( )No máximo de 2 a 3 vezes ao ano ( 7 a 8 pontos); ( )Sempre que aparece as oportunidades (9 a 10 pontos); 10 - Você tem informações suficientes para as desenvolver as atividades diárias? ( ) Não tenho informações (0 a 1 ponto); ( )Pouca informação ( 2 a 4 pontos); ( )Tenho parcialmente as informações que preciso ( 5 a 6 pontos); ( )Na maioria dos casos, disponho das informações (7 a 8 pontos); ( Sempre disponho das informações (9 a 10 pontos).

Observações: Durante a entrevista, os entrevistados não tiveram acesso aos scores que seriam atribuídos a cada resposta. Maioria dos itens tem-se uma faixa de nota, sendo considerado todo o contexto da entrevista e se a resposta se aproxima mais do nível anterior ou posterior para a atribuição da pontuação. Fonte: Autores. 


\section{Resultados}

A maioria dos entrevistados pertencem ao gênero feminino, com idade entre 20 a 40 anos (n= 18, 85,7\%), do gênero feminino $(n=18,85,7 \%)$ e predominou os responsáveis técnicos $(n=15,71,4 \%)$ pelas drogarias e estes relataram não possuir outro farmacêutico no seu horário de trabalho, porém a maioria das drogarias prestam algum serviço farmacêuticos.

Os profissionais relataram, em sua maioria, satisfeito com o acesso aos serviços de saúde (Tabela 2), porém uma limitação do instrumento é se estes utilizam os serviços do Sistema Único de saúde ou possuem planos de saúde.

Como pontos positivos, muitos farmacêuticos ressaltaram questões relacionadas ao reconhecimento profissional, enquanto outros destacaram aspectos econômicos. A sobrecarga de trabalho e múltiplas tarefas foram citadas como pontos negativos por alguns entrevistados. Quando perguntados o que mudariam, muitos sugeriram elevar o número de funcionários na loja (Tabela 2).

Tabela 2 - Breve perfil dos farmacêuticos incluídos no estudo.

\begin{tabular}{|c|c|}
\hline & Breve descrição \\
\hline 1-RT, F. & $\begin{array}{l}\text { 40-50anos, > } 15 \text { anos de profissão, não outro farmacêutico no turno, não tem serviço farmacêutico; sistema de } \\
\text { saúde adequado. Ponto positivo: valorização e respeito social; negativo= exposição aos patógenos; mudança a } \\
\text { forma de contato com o público para evitar contaminação. }\end{array}$ \\
\hline 2-RT & $\begin{array}{l}\text { 20-30 anos; <5 anos de profissão; não outro farmacêutico no turno, acesso sistema de saúde satisfatório; ponto } \\
\text { += próprio serviço; negativo= difícil lançar as receitas no balcão; mudança: sistema de lançamento em } \\
\text { computador interno }\end{array}$ \\
\hline 3-RT-F & $\begin{array}{l}\text { 40-50anos, 10-15 anos de profissão, não outro farmacêutico no turno, vários serviços farmacêuticos; sistema de } \\
\text { saúde satisfatório, ponto positivo aspecto financeiro; negativo- falta de tempo para outras atividades; se } \\
\text { pudesse aumentaria o tempo de lazer }\end{array}$ \\
\hline 4-GF, F & $\begin{array}{l}\text { 20-30anos, <5 anos na profissão, tem outro farmacêutico no mesmo horário, vários serviços farmacêuticos; } \\
\text { muito satisfeito com serviço de saúde, ponto positivo poder liderar, ponto negativo=pressão psicológica. Relata } \\
\text { que recebeu treinamento e não são informados }\end{array}$ \\
\hline 5-RT, F. & $\begin{array}{l}\text { 30-40 anos, } 5 \text { a } 10 \text { anos de profissão, moderada satisfação com o serviço de saúde, não tem outro } \\
\text { farmacêutico, apenas atenção farmacêutica, não vê nenhum ponto negativo e sugere aumento da bonificação } \\
\text { do RT para } 20 \% \text {, ponto positivo é experiencia profissional e salário }\end{array}$ \\
\hline 6-GT, F & $\begin{array}{l}\text { 20-30anos, }<5 \text { anos de profissão, existe farmacêutico no horário de trabalho, não tem serviços. Ponto positivo- } \\
\text { aprendizado pessoal, profissional e aumento da competência social, negativo a falta de reconhecimento; } \\
\text { mudaria a capacitação dos funcionária aumentando }\end{array}$ \\
\hline $7-\mathrm{RT}$ & $\begin{array}{l}20-30 \text { anos, }<5 \text { anos de formado, não há outro colega durante o turno de trabalho, presta atenção } \\
\text { farmacêutica, como ponto positivo destaca o atendimento a população, negativo a sobrecarga de trabalho e se } \\
\text { pudesse aumentaria o número de funcionários }\end{array}$ \\
\hline 8- RT, F & $\begin{array}{l}\text { 20-30anos, 5-10 anos de experiência profissional; presta a atenção farmacêutica; insatisfeito com o acesso aos } \\
\text { serviços de saúde; ponto positivo- salário; negativo- muitas cobranças; faria várias mudanças }\end{array}$ \\
\hline 9- RT, F. & $\begin{array}{l}\text { 20-30anos, <5 anos de experiência profissional; presta a atenção farmacêutica a PA; não tem outro } \\
\text { farmacêutico em seu turno, insatisfeito com o acesso aos serviços de saúde; ponto positivo- auxiliar e ajudar as } \\
\text { pessoas; negativo- realizar atividades de balconista dificulta realizar a parte administrativa; mudanças- mais } \\
\text { funcionários para a loja }\end{array}$ \\
\hline 10-RT, F & $\begin{array}{l}\text { 20-30anos, 5- } 10 \text { anos de experiência profissional; vários serviços farmacêuticos; tem outro farmacêutico em } \\
\text { seu turno, satisfeito com o acesso aos serviços de saúde; ponto positivo- dinamismo; negativo- salário } \\
\text { incompatível com o número de atividades desenvolvidas e demanda; mudanças- mais funcionários para a loja }\end{array}$ \\
\hline 11-RT, F & $\begin{array}{l}\text { 30-40anos, <5-anos de experiência profissional; vários serviços farmacêuticos; não tem outro farmacêutico em } \\
\text { seu turno, satisfeito com o acesso aos serviços de saúde; ponto positivo- conhecimento adquirido e o } \\
\text { reconhecimento pelos clientes; negativo- elevada responsabilidade que o cargo exige; mudanças- programa } \\
\text { que facilitasse a parte burocrática }\end{array}$ \\
\hline 12-GF, F & $\begin{array}{l}\text { 30-40anos, 5-10 anos de experiência profissional; vários serviços farmacêuticos; não tem outro farmacêutico } \\
\text { em seu turno, muito satisfeito com o acesso aos serviços de saúde; ponto positivo- desenvolvimento } \\
\text { profissional, credibilidade e visibilidade; negativo- multitarefa que consome o tempo para estratégias } \\
\text { gerenciais; mudanças- mais funcionários e layout da loja }\end{array}$ \\
\hline 13-GF, F & $\begin{array}{l}\text { 40-50anos, >15 anos de experiência profissional; vários serviços farmacêuticos; não tem outro farmacêutico em } \\
\text { seu turno, satisfeito com o acesso aos serviços de saúde; ponto positivo- conhecimento mais amplo; negativo e } \\
\text { mudanças- sem resposta }\end{array}$ \\
\hline 14-RT, F & $\begin{array}{l}\text { 30-40anos, 5-10 anos de experiência profissional; vários serviços farmacêuticos; não tem outro farmacêutico } \\
\text { em seu turno, moderadamente satisfeito com o acesso aos serviços de saúde; ponto positivo- salário em dia; } \\
\text { negativo- fazer atividades que não são de RT, mudanças- proibir transferência entre lojas }\end{array}$ \\
\hline 15-RT, F & $\begin{array}{l}\text { 30-40anos, }<5 \text { anos de experiência profissional; vários serviços farmacêuticos; não tem outro farmacêutico em } \\
\text { seu turno, satisfeito com o acesso aos serviços de saúde; ponto positivo- autonomia para decidir o que fazer e } \\
\text { flexibilidade de horário; negativo- desvalorização profissional, mudanças- melhoria no atendimento }\end{array}$ \\
\hline 16-RT, F & $\begin{array}{l}\text { 20-30anos, }<5 \text { anos de experiência profissional; não tem serviços farmacêuticos; não tem outro farmacêutico } \\
\text { em seu turno, muito satisfeito com o acesso aos serviços de saúde; ponto positivo- liderança e assistência à }\end{array}$ \\
\hline
\end{tabular}




\begin{tabular}{ll}
\hline & saúde; negativo- desvalorização profissional, mudanças- não \\
\hline 17-GF, F & 20-30anos, 5-10 anos de experiência profissional; atenção farmacêutica; não tem outro farmacêutico em seu \\
& turno, satisfeito com o acesso aos serviços de saúde; ponto positivo- aprendizagem de liderança; negativo- \\
& múltiplas tarefas, mudanças- gerenciamento da Clínica Farmacêutica dentro da loja \\
\hline 18-RT, F & 20-30anos, <5anos de experiência profissional; atendimento e orientação; não tem outro farmacêutico em seu \\
& turno, satisfeito com o acesso aos serviços de saúde; ponto positivo- respeito; negativo- carga horária, \\
& mudanças- carga horária \\
\hline 19- GF, F & 30-40anos, 5-10anos de experiência profissional; não tem serviço farmacêutico; não tem outro farmacêutico \\
& em seu turno, satisfeito com o acesso aos serviços de saúde; ponto positivo- acesso a informações e gerenciar \\
& pessoas; negativo- múltiplas atividades, mudanças-agilizaria alguns processos \\
\hline 20-RT, F & $\begin{array}{l}\text { 30-40anos, 10-15anos de experiência profissional; atenção farmacêutica; não tem outro farmacêutico em seu } \\
\text { turno, moderadamente satisfeito com o acesso aos serviços de saúde; ponto positivo- aprendizagem; negativo- } \\
\text { não tem autonomia, mudanças-funcionário }\end{array}$ \\
\hline 30-40anos, 5-10anos de experiência profissional; atenção farmacêutica; não tem outro farmacêutico em seu \\
turno, insatisfeito com o acesso aos serviços de saúde; ponto positivo- reconhecimento, gratificação, \\
aprendizagem e experiência; negativo- sem pontos, mudanças-funcionário e aumentar o número
\end{tabular}

Legenda: RT- responsável técnica, GF- Gerente farmacêutico; F- feminino; PA- pressão arterial. Fonte: Autores.

No domínio biológico, vários farmacêuticos $(\mathrm{n}=9 ; 42,6 \%)$ apresentam problemas de sono e alguns relatam de falta de energia $(n=5 ; 23,8 \%)$. Esta falta de energia pode ter relação a síndrome de Burnout e, por isso, é importante investigar. Alguns farmacêuticos relataram uma percepção ruim da saúde $(n=9 ; 42,6 \%)$, merecendo uma melhor investigação. Além disso, vários farmacêuticos relataram qualidade no sono, excelente energia e percepção de saúde positiva ( $\mathrm{n}=8 ; 38 \%)$ (Tabela 3).

Tabela 3: Analise do domínio I que envolve aspectos biológicos

\begin{tabular}{lcccc}
\hline & Sono & energia & saúde & Média do domínio (classificação), sugestão \\
\hline 1 & 8 & 8 & 10 & 8,66 (muito bom) \\
2 & 8 & 8 & 8 & 8 (muito bom) \\
3 & 5 & 7 & 4 & 5,4 (bom), encaminhar ao serviço médico \\
4 & 4 & 7 & 7 & 6,0 (bom), investigar o problema no sono \\
5 & 5 & 9 & 7 & 7,0 (bom), investigar o problema no sono \\
6 & 5 & 3 & 1 & 3,0 (ruim), investigar Burnout \\
7 & 8 & 8 & 8 & 8 (muito bom) \\
8 & 1 & 2 & 0 & 1 (ruim), investigar Burnout \\
9 & 7 & 7 & 4 & 6,0 (bom), encaminhar ao serviço médico \\
10 & 6 & 7 & 3 & 5,3 (bom), encaminhar ao serviço médico \\
11 & 10 & 10 & 8 & 9,3 (ótimo) \\
12 & 10 & 10 & 8 & 9,3 (ótimo) \\
13 & 10 & 8 & 8 & 8,66 (muito bom) \\
14 & 6 & 7 & 7 & 6,66 (bom) \\
15 & 8 & 10 & 8 & 8,66 (muito bom) \\
16 & 8 & 8 & 6 & 7,3 (muito bom) \\
17 & 10 & 10 & 8 & 9,3 (ótimo) \\
18 & 8 & 5 & 5 & 6 (bom), investigar Burnout \\
19 & 5 & 9 & 0 & 3 (ruim), investigar Burnout \\
20 & 5 & 2 & 2 & 6,3 (bom), investigar Burnout \\
21 & 7 & 5 & 7 & 4,6 (ruim), encaminhar ao serviço médico \\
\hline
\end{tabular}

Média < 5,0 ruim; 5,0 até 6,9- bom; 7,0 até 8,9- muito bom; $\geq 9,0$ ótimo. Fonte: Autores.

Quando se utiliza este método para avaliar, de forma preliminar, dimensões psicológicas várias alterações foram detectadas. Em alguns farmacêuticos foi possível detectar sua percepção de baixa qualidade de vida; o pouco ou falta de sentido da vida; que alternam momentos de segurança na tomada de decisão com insegurança; acham que o trabalho impacta, em alguma extensão, em sua aparência; e demonstram insatisfação consigo mesmo (Tabela 4).

No domínio II< onde se avaliou os aspectos psicológicos, observou-se farmacêutico com ótimo nível (n=3;14,2\%), muito bom ( $n=6 ; 28,5 \%)$, bom e merecendo atenção em algum aspecto $(n=6 ; 28,5 \%)$ e em situação muito preocupante ( $n=2$; 9,5\%) (Tabela 4). 
Tabela 4 - Análise do domínio II que envolve aspectos psicológicos.

\begin{tabular}{|c|c|c|c|c|c|c|c|}
\hline & 10 & 29 & 3은 & 40 & 5은 & 60 & Média do domínio (classificação) sugestões \\
\hline 1 & 8 & 10 & 10 & 10 & 10 & 6 & 9 (ótimo) \\
\hline 2 & 8 & 10 & 8 & 10 & 10 & 9 & 9,3 (ótimo) \\
\hline 3 & 4 & 9 & 7 & 9 & 7 & 7 & 7,1 (muito bom)* \\
\hline 4 & 7 & 4 & 7 & 5 & 7 & 5 & 5,8 (bom), investigar a falta de sentido da vida e a insatisfação pessoa \\
\hline 5 & 7 & 9 & 7 & 7 & 7 & 5 & 7,0(muito bom)* \\
\hline 6 & 1 & 3 & 5 & 9 & 3 & 3 & 4,0(ruim) encaminhar ao serviço médico \\
\hline 7 & 8 & 10 & 8 & 8 & 8 & 8 & 8,3 (muito bom) \\
\hline 8 & 3 & 1 & 1 & 5 & 4 & 1 & 2,5 (ruim) encaminhar ao serviço médico \\
\hline 9 & 5 & 9 & 7 & 7 & 7 & 5 & 6,6 (bom) merece uma atenção especial \\
\hline 10 & 7 & 7 & 7 & 7 & 5 & 5 & 6,3 (bom) merece uma atenção especial \\
\hline 11 & 10 & 10 & 8 & 10 & 10 & 10 & 9,66 (ótimo) \\
\hline 12 & 8 & 10 & 8 & 10 & 8 & 6 & 8,3 (muito bom) \\
\hline 13 & 8 & 10 & 8 & 8 & 6 & 8 & 8,0 (muito bom) \\
\hline 14 & 7 & 5 & 7 & 7 & 7 & 5 & 6,3 (bom)* \\
\hline 15 & 8 & 10 & 8 & 8 & 8 & 8 & 8,3 (muito bom) \\
\hline 16 & 5 & 9 & 7 & 7 & 7 & 5 & $6,6(\mathrm{bom})^{*}$ \\
\hline 17 & 7 & 9 & 5 & 7 & 5 & 7 & $6,6(\mathrm{bom})^{*}$ \\
\hline 18 & 5 & 7 & 5 & 7 & 5 & 5 & 5,6 (bom) merece uma atenção especial \\
\hline 19 & 6 & 10 & 10 & 8 & 8 & 10 & 8,66 (muito bom)* \\
\hline 20 & 5 & 5 & 5 & 7 & 7 & 5 & 5,66 (bom) merece uma atenção especial \\
\hline 21 & 7 & 7 & 5 & 5 & 7 & 5 & 6,0 (bom) merece uma atenção especial \\
\hline
\end{tabular}

$1^{\circ}$ Percepção da qualidade de vida; $2^{\circ}$ Sentido da vida; $3^{\circ}$ capacidade de concentração; $4^{\circ}$ segurança na tomada de decisão; $5^{\circ}$ percepção da aparência e $6^{\circ}$ satisfação consigo mesmo. Média do domínio < 5,0 ruim; 5,0 até 6,9- bom; 7,0 até 8,9- muito bom; $\geq 9,0$ ótimo. *Resultados contraditórios e merece uma investigação. Fonte: Autores.

Em relação ao domínio III que visa avaliar o nível de independência do profissional farmacêutico, exceto 2 profissionais, todos disseram que existem procedimentos operacionais padrão (POP) que normatiza deste a questão da hierarquia, até as práticas rotineiras da drogaria. Neste contexto, não é possível o gerente farmacêutico ou responsável técnico fazer grandes mudanças. Alguns relaram pequenas melhorias nas relações humanas, nos atendimentos e outros não puderam fazer nenhuma alteração no serviço. Apenas, 1 profissional, cuja farmácia não tinha POP, relatou que fez pequenas mudanças estruturais (Tabela 7).

Outro domínio avaliado envolve as relações sociais e impacto do trabalho na vida pessoal do farmacêutico e os resultados obtidos são preocupantes. A maioria dos entrevistados possui algum enfrentamento neste domínio, ou várias questões demonstram a dificuldade de relações sociais e seu impacto na vida pessoal (Figura 5). Estes resultados demonstram a importância de se ter na empresa um setor que possa acolher o funcionário, tenha cursos de capacitação que visem melhorar as relações sociais. 
Tabela 5 - Análise do domínio IV das relações sociais.

\begin{tabular}{cccccccc}
\hline & $\mathbf{1 0}$ & $\mathbf{2 0}$ & 3o & $\mathbf{4 0}$ & $\mathbf{5 0}$ & $\mathbf{6 0}$ & Média (classificação) sugestões \\
\hline 1 & 7 & 5 & 9 & 4 & 7 & 7 & 6,5 (bom) merece uma atenção especial \\
2 & 9 & 7 & 7 & 4 & 7 & 9 & 6,5 (bom) merece uma atenção especial \\
3 & 4 & 7 & 7 & 4 & 4 & 0 & 4,3 (ruim) encaminhar ao serviço de acolhimento \\
4 & 7 & 5 & 5 & 4 & 4 & 9 & 6,0 (bom) merece uma atenção especial* \\
5 & 9 & 5 & 5 & 7 & 9 & 5 & 6,6 (bom) merece uma atenção especial* \\
6 & 5 & 5 & 5 & 1 & 3 & 1 & 3,3 (ruim) encaminhar ao serviço de acolhimento \\
7 & 7 & 7 & 5 & 5 & 7 & 7 & 6,6 (bom) merece uma atenção especial* \\
8 & 3 & 3 & 5 & 1 & 1 & 1 & 2,3 (ruim) encaminhar ao serviço de acolhimento \\
9 & 8 & 8 & 10 & 8 & 8 & 8 & 8,3 (muito bom) \\
10 & 5 & 5 & 7 & 3 & 7 & 9 & 6,0 (bom) merece uma atenção especial* \\
11 & 10 & 8 & 8 & 8 & 10 & 10 & 9,0 (ótimo) \\
12 & 9 & 7 & 9 & 4 & 7 & 5 & $6,8($ bom) merece uma atenção especial* \\
13 & 7 & 7 & 7 & 5 & 7 & 7 & 6,6 (bom) merece uma atenção especial* \\
14 & 4 & 7 & 7 & 5 & 7 & 9 & $6,5($ bom) merece uma atenção especial* \\
15 & 7 & 7 & 4 & 7 & 7 & 5 & 6,1 (bom) merece uma atenção especial* \\
16 & 8 & 8 & 10 & 8 & 8 & 8 & 8,3 (muito bom) \\
17 & 7 & 7 & 9 & 4 & 7 & 7 & 6,8 (bom) merece uma atenção especial* \\
18 & 5 & 7 & 9 & 4 & 5 & 9 & 6,5 (bom) merece uma atenção especial* \\
19 & 7 & 9 & 7 & 4 & 7 & 9 & 7,1 (bom) merece uma atenção especial* \\
20 & 7 & 3 & 3 & 5 & 5 & 5 & 4,6 (ruim) encaminhar ao serviço de acolhimento \\
21 & 7 & 5 & 5 & 5 & 7 & 9 & 6,3 (bom) merece uma atenção especial* \\
\hline
\end{tabular}

$1^{\circ}$ relações pessoais; $2^{\circ}$ relações profissionais; $3^{\circ}$ trabalho colaborativo; $4^{\circ}$ impacto do trabalho na vida pessoal; $5^{\circ}$ concili ação do trabalho com a vida pessoal; $6^{\circ}$ qualidade da vida sexual. média $<5,0$ ruim; 5,0 até 6,9 - bom; 7,0 até 8,9- muito bom; $\geq 9,0$ ótimo. *Resultados contraditórios e merece uma investigação. Fonte: Autores.

Tabela 6 - Avaliação dos aspectos relacionados ao trabalho e moradia (domínio V).

\begin{tabular}{cccccccccccc}
\hline & 19 & 20 & 30 & 40 & 50 & 60 & 70 & $\mathbf{8}$ - & 9o & 10o & Média (classificação) \\
\hline 1 & 8 & 10 & 8 & 8 & 10 & 6 & 8 & 8 & 6 & 10 & 8,2 (muito bom)* \\
2 & 8 & 10 & 10 & 8 & 10 & 8 & 6 & 10 & 10 & 10 & 9,0 (ótimo) \\
3 & 7 & 5 & 5 & 7 & 9 & 7 & 4 & 7 & 4 & 9 & 6,3 (bom)* \\
4 & 5 & 5 & 7 & 9 & 7 & 7 & 4 & 9 & 9 & 7 & 6,9 (bom)* \\
5 & 5 & 7 & 7 & 5 & 4 & 7 & 5 & 9 & 5 & 7 & 6,1 (bom)* \\
6 & 5 & 5 & 7 & 3 & 1 & 5 & 5 & 5 & 4 & 7 & 4,7 (ruim) \\
7 & 4 & 5 & 9 & 7 & 7 & 5 & 7 & 7 & 7 & 5 & 6,3 (bom)* \\
8 & 4 & 3 & 9 & 1 & 1 & 1 & 2 & 5 & 3 & 5 & 3,4 (ruim) \\
9 & 5 & 7 & 5 & 5 & 5 & 7 & 5 & 7 & 7 & 7 & 6,0 (bom)* \\
10 & 4 & 5 & 7 & 7 & 1 & 5 & 7 & 9 & 7 & 7 & 5,9 (bom)* \\
11 & 8 & 10 & 8 & 8 & 6 & 10 & 8 & 10 & 8 & 8 & 8,4 (muito bom) \\
12 & 5 & 4 & 9 & 9 & 4 & 7 & 5 & 9 & 7 & 7 & 6,6 (bom)* \\
13 & 5 & 7 & 9 & 7 & 7 & 7 & 7 & 9 & 3 & 7 & 6,8 (bom)* \\
14 & 7 & 7 & 9 & 7 & 7 & 9 & 4 & 9 & 5 & 7 & 7,1 (muito bom)* \\
15 & 5 & 5 & 9 & 7 & 4 & 7 & 7 & 9 & 7 & 7 & 6,7 (bom)* \\
16 & 7 & 9 & 7 & 5 & 7 & 7 & 1 & 9 & 7 & 7 & 6,6 (bom)* \\
17 & 6 & 8 & 10 & 10 & 8 & 8 & 8 & 10 & 8 & 8 & 8,4 (muito bom) \\
18 & 7 & 4 & 9 & 7 & 4 & 7 & 7 & 4 & 4 & 7 & 6,0 (bom)* \\
19 & 5 & 5 & 9 & 6 & 4 & 7 & 7 & 9 & 9 & 7 & 6,8 (bom)* \\
20 & 3 & 9 & 9 & 7 & 4 & 3 & 3 & 9 & 9 & 7 & 6,3 (bom)* \\
21 & 3 & 9 & 9 & 9 & 4 & 3 & 7 & 9 & 5 & 5 & 6,3 (bom)* \\
\hline
\end{tabular}

$1^{\circ}$ satisfação com o salário; $2^{\circ}$ jornada de trabalho; $3^{\circ}$ distancia entre a casa e o trabalho; $4^{\circ}$ satisfação com a moradia; $5^{\circ}$ avaliação do número de atividades desenvolvidas; $6^{\circ}$ desempenho; $7^{\circ}$ frequência do lazer; $8^{\circ}$ férias; $9^{\circ}$ oportunidade para capacitação; $10^{\circ}$ informações suficientes para a realização das atividades. média $<5,0$ ruim; 5,0 até 6,9- bom; 7,0 até 8,9- muito bom; $\geq 9,0$ ótimo. *Resultados contraditórios e merece uma investigação. Fonte: Autores.

O domínio que mais impactou negativamente na qualidade de vida dos farmacêuticos entrevistados é nível de independência. Em especial os profissionais 6 e 8 apresentaram alterações em todos os domínios e merecem uma atenção especial. $\mathrm{O}$ domínio com menores índices foi o que avaliou a independência do profissional Baseado nas médias obtidas, $\mathrm{o}$ nível de qualidade de vida foi baixo a mediano (Tabela 7). 
Tabela 7 - Avaliação da qualidade de vida dos farmacêuticos.

\begin{tabular}{|c|c|c|c|c|c|c|c|}
\hline & \multicolumn{5}{|c|}{ Médias } & \multirow{2}{*}{$\begin{array}{l}\text { Média } \\
\text { QV }\end{array}$} & \multirow[t]{2}{*}{ comentários } \\
\hline & DI & DII & DIII & DIV & DV & & \\
\hline 1 & 8,66 & 9,0 & 1,0 & 6,5 & 8,2 & 6,7 mediana & Baixo nível de independência \\
\hline 2 & 8,0 & 9,3 & 3,0 & 6,5 & 9,0 & 7,16 mediana & Baixo nível de independência \\
\hline 3 & 5,4 & 7,1 & 0,0 & 4,3 & 6,3 & 4,6 baixa & $\begin{array}{l}\text { Baixo nível de independência, relações } \\
\text { sociais }\end{array}$ \\
\hline 4 & 6,0 & 5,8 & 0,0 & 6,0 & 6,9 & 4,94 baixa & Baixo nível de independência \\
\hline 5 & 7,0 & 7,0 & 0,0 & 6,6 & 6,1 & 5,34 mediana & Baixo nível de independência \\
\hline 6 & 3,0 & 4,0 & 3,0 & 3,3 & 4,7 & 3,6 baixa & Baixo nível de independência \\
\hline 7 & 8,0 & 8,3 & 2,0 & 6,6 & 6,3 & 6,24 mediana & Baixo nível de independência \\
\hline 8 & 1,0 & 2,5 & 3,0 & 2,3 & 3,4 & 2,44 baixa & Baixo nível de independência \\
\hline 9 & 6,0 & 6,6 & 0,0 & 8,3 & 6,0 & 5,38 mediana & Baixo nível de independência \\
\hline 10 & 5,3 & 6,3 & 0,0 & 6,0 & 5,9 & 3,51 baixa & Baixo nível de independência \\
\hline 11 & 9,3 & 9,66 & 2,0 & 9,0 & 8,4 & 7,67 mediana & Baixo nível de independência \\
\hline 12 & 9,3 & 8,3 & 0,0 & 6,8 & 6,6 & 6,2 mediana & Baixo nível de independência \\
\hline 13 & 8,66 & 8,0 & 0,0 & 6,6 & 6,8 & 6,0 mediana & Baixo nível de independência \\
\hline 14 & 6,66 & 6,3 & 0,0 & 6,5 & 7,1 & 5,31 mediana & Baixo nível de independência \\
\hline 15 & 8,66 & 8,3 & 4,0 & 6,1 & 6,7 & 6,75 mediana & Baixo nível de independência \\
\hline 16 & 7,3 & 6,6 & 0,0 & 8,3 & 6,6 & 6,22 mediana & Baixo nível de independência \\
\hline 17 & 9,3 & 6,6 & 2,0 & 6,8 & 8,4 & 6,62 mediana & Baixo nível de independência \\
\hline 18 & 6,0 & 5,6 & 0,0 & 6,5 & 6,0 & 4,82 baixa & Baixo nível de independência \\
\hline 19 & 4,6 & 8,66 & 0,0 & 7,1 & 6,8 & 5,43 mediana & Baixo nível de independência \\
\hline 20 & 3,0 & 5,6 & 5,0 & 4,6 & 6,3 & 4,8 baixa & $\begin{array}{l}\text { Baixo nível de independência, biológicos } \\
\text { e relações sociais }\end{array}$ \\
\hline 21 & 6,3 & 6,0 & 0,0 & 6,3 & 6,3 & 4,98 baixa & Baixo nível de independência \\
\hline
\end{tabular}

DI-biológico; DII- psicológico, DIII- nível de independência, DIV- relações sociais, DV-trabalho e moradia. média $\leq$ 5,0 baixa qualidade de vida; entre 5,1-8,0 qualidade de vida mediana; > 8,1- boa qualidade de vida. Fonte: Autores.

\section{Discussão}

Quando se fala em qualidade de vida, esta deve ser entendida como uma percepção individual que cada pessoa tem sobre si, sendo que vários fatores podem interferir nesta como grau de satisfação amorosa, familiar, social, ambiental, financeira, estética, cultural e existencial (Baldoino \& Santos, 2020). Ainda são escassos os estudos que visem avaliar a qualidade de vida entre farmacêuticos, em especial, que exercem seu oficio em rede de drogarias.

O gerente farmacêutico (GF), como qualquer gerente, deve administrar, planejar, dirigir, organizar e controlar as atividades relacionadas ao serviço e as pessoas envolvidas no serviço (Braverman, 1981; Mattos, 1985). O GF precisa lidar com pessoas, sendo o responsável pelo cumprimento das normas organizacionais e alcance das metas e deve ser avaliado através do desempenho de sua equipe. Assim, para desempenhar a função de GF, o profissional deve ter conhecimentos e habilidades nas dimensões técnicas, administrativas, políticas e psicossociais (Junqueira, 1990).

O farmacêutico responsável técnico (RT) é responsável pelas atividades burocráticas técnicas da loja, sendo responsável por todas as tramitações perante o Conselho Regional de farmácia, bem como vigilância sanitária. Ainda, está sob sua responsabilidade a realização, supervisão e coordenação de todos os serviços técnico-científicos do estabelecimento. Além disso, os RT ainda prestam atenção farmacêutica e realizam outros serviços farmacêuticos. Logo, são muitas atividades desenvolvidas e podem estar associadas a longas jornadas de trabalho, que podem impactar na percepção da saúde, qualidade de vida e dar sensação de falta de energia ou esgotamento. O esgotamento pode sugerir que o trabalhador está com síndrome de Burnout e existe uma estreita relação desta com a baixa qualidade do sono (Moreira, et al., 2020).

Alguns profissionais relataram que nem sempre percebem o sentido da vida, podendo sinalizar um quadro de depressão. Na depressão pode ocorrer a sensação de falta de sentido na vida ou de vazio existencial, sendo importante realizar intervenções (Aquino, Dara \& Simeão, 2016). Quando se fala em sentido da vida deve-se pensar em sua relevância para a saúde mental (Frankl, 1989) e não se deve desconsiderar a queixa o relato do profissional. 
Poucos farmacêuticos relataram que o exercício da profissão impactou negativamente, em alguma extensão, em sua aparência. A imagem do profissional pode ser associada a poder, reconhecimento e status e a projeção de uma imagem negativa pode impactar no desenvolvimento da profissão e em seu reconhecimento social (Santos, et al., 1988; Nauderer \& Lima, 2005).

Alguns profissionais demonstraram satisfação mediana e baixa e dificuldade de concentração, podendo ser um sinalizador da síndrome de Burnout (Pêgo \& Pêgo, 2016). As drogarias são estabelecimentos de saúde, porém possuem especificidades. Na rotina de trabalho nesses locais, os farmacêuticos precisam lidar com questões administrativas e com queixas de pacientes clientes, como dor, mal-estar e outros problemas. Neste contexto, é importante que o profissional tenha competências interpessoais e sabiam lidar com forte pressões e longas jornadas (Fabichak, Silva-Junior \& Morrone, 2014). Logo, é importante que o farmacêutico estabeleça boas relações com sua equipe e possa contar com sua colaboração.

Neste estudo, identificou-se que alguns profissionais estão enfrentando problemas de relações profissionais e não podem contar plenamente com a colaboração de seus pares. $\mathrm{Na}$ análise das relações de trabalho deve-se considera como se desenvolve o processo de trabalho e compreender os seus componentes visando à obtenção de um resultado (Atos, Pires \& Campos, 2009). No caso dos farmacêuticos é importante que reconheçam a importância das relações interpessoais, pois estas interferem no cuidado prestado ao cliente (Wagner, et al., 2009). Ressalta-se que o trabalho em equipe, onde existe uma colaboração entre os membros, permite elevar a efetividade do trabalho e elevar a satisfação do trabalhador (Piancastelli, Faria $\&$ Silveira, 2000).

Nas ultimas década, houve intensas transformações sociais, familiares e organizacionais, resultando em novas exigências nos campos do trabalho e familiar, sendo um grande desafio o equilíbrio entre estes (Souza, 2007). Algumas consequências da coesão de papéis da vida pessoal e do trabalho são problemas nas relações familiares e afetivas, insatisfação com o trabalho (Tremblay, 2004). Em contrapartida, a relação equilibrada entre a família e o trabalho traz benefícios para o trabalhador e para a organização, pois gera satisfação e motivação nos trabalhadores na realização de suas atividades (Chambel \& Santos, 2009; Eddleston \& Powell, 2012)

Um aspecto muito importante é a conciliação do trabalho-família, isto é, a existência de uma relação salutar entre o contexto profissional e familiar (Teixeira \& Nascimento, 2011). No entanto, nem todos os profissionais conseguem uma conciliação adequada entre estes (Tabela 3) e sabe-se que este equilíbrio acontece quando se tem disponibilidade de meios e o tempo suficiente para cuidar da família, não sendo negligenciado papel profissional (Goméz, 2003).

O trabalho pode impactar positivamente a vida do trabalhador, porém a sobrecarga de trabalho pode afetar a saúde geral e mental, danos em sua vida profissional, nos aspectos sociais e comportamentais (Ishara, 2007; Rebouças, Legay \& Abelha, 2007) maior frequência de absenteísmo, rotatividade e estresse, comprometendo a qualidade do serviço prestado (Barbosa \& Buesso, 2019). Deste modo, o trabalho pode impactar de forma muito negativa na vida pessoal.

Apesar de a maioria dos entrevistados demonstrarem satisfação com a vida sexual, 28,5\% relatam baixa qualidade quanto a esta temática. A sexualidade pode ser definida como uma forma de energia que motiva a procurar amor, contato, intimidade, que se integra e permite a toca de carícias. Também, a sexualidade influencia pensamentos, sentimentos, ações e interações, e tem consequências na saúde física e mental. Em síntese, a sexualidade envolve a interação entre fatores biológicos, psicológicos, sociais, culturais e históricos e estende-se ao longo de todo o ciclo vital (Ramos 2018). No caso de um adulto queixar de problemas na sexualidade deve-se investigar fatores biológicos, psicológicos, sociais, culturais e históricos, e fazer a intervenção adequada, se possível.

Vários fatores contribuem para independência, autonomia e visibilidade do profissional, tais como: a formação em nível superior; portar títulos de especialização, mestrado ou doutorado; o desenvolvimento científico da área; a qualidade da formação do profissional e o desempenho profissional; reconhecimento legal da profissional e órgãos de classes fortes (Abreu, 
2001; Nunes, 2003; Ribeiro, 2009). A profissão farmacêutica possui todos estes fatores, entretanto o nível de independência e autonomia dos profissionais nas redes de drogarias é baixo, pois existe POP que devem seguir.

De acordo com Gonçalves e colaboradores (2013), em alguns segmentos a padronização dos processos se deve as demandas do mercado e visa manter a o controle de qualidade de todo o processo, em especial de processos repetitivos. Ainda se aponta algumas vantagens da padronização dos processos, pois permite a manutenção da previsibilidade dos resultados; a facilitando o rastreamento dos erros e sua correção; facilita o envolvimento dos funcionários na busca pela qualidade. No entanto, esta padronização excessiva possui algumas desvantagens como: absenteísmo, altas taxas de rotatividade, falta de comprometimento com a organização e outros (Gonçalves, et al., 2013)

A falta de autonomia dos farmacêuticos na tomada de decisões, tendo que seguir o estabelecido em POP, pode gerar um estado de estresse crônico, podendo aumentar a incidência de Burnout. Tal fato pode contribuir para redução da qualidade de serviços, os altos índices de absenteísmo dos profissionais (Pavlakis, Raftopoulos \& Mamas, 2010; Moreira, et al, 2009), deterioração do bem-estar físico e emocional. Este profissional pode reclamar de exaustão, frequentemente estar doente, sofrer de insônia, entre outras doenças (Carlotto, 2010; Carvalho \& Magalhães, 2011).

Em cidades como São Paulo e Rio de Janeiro, muitas vezes, os trabalhadores gastam um tempo prolongado para chegar ao trabalho, entretanto no presente estudo todos os farmacêuticos moravam próximo ou relativamente próximos ao trabalho e o nível de satisfação com a moradia foi elevado. Quando existe um longo deslocamento entre a casa e o trabalho, além do desconforto e perda de qualidade de vida, ainda há menos disponibilidade de tempo para qualificação do profissional e, ao longo dos anos, este terá menor participação na força do trabalho (Young, Aguiar e Gema, 2013).

Muitos entrevistados demonstraram baixa a mediana satisfação com o salário e isso pode impactar negativamente na motivação do profissional (Batista, et al., 2005). A satisfação com o salarial é considerada um fator importante motivacional, pois gera no profissional a sensação de reconhecimento e progresso na carreira (Maslow, 1968). O reconhecimento representa um elemento importante para o desempenho profissional. Entre os fatores que motivam a insatisfação no trabalho estão a remuneração, o salário inicial, as exigências feitas pelo empregador, a carga horária, e como os profissionais lidam com estes fatores (Batista, et al., 2005).

A saúde no trabalho é essencial para o desenvolvimento socioeconômico de uma nação. O momento exige cada vez mais trabalhadores criativos e qualificados, porém as condições de trabalho e nível salarial são cada vez mais precários. Os custos que as pessoas estressadas representam para as instituições não são considerados e nem as consequências da sobrecarga de trabalho (Waldow, 1999; Silva, et al., 2006). A sobrecarga de trabalho ocasiona a falta de tempo para o profissional descansar, refletir, organizar, aprender e acaba causando desgaste físico e emocional (Silva, et al., 2006).

A maioria dos entrevistados relatam ter férias e incluir o lazer de forma semanal ou mensal. O lazer traz muitos benefícios para a vida do trabalhador, como o combate ao estresse, trazendo equilíbrio no meio interno do corpo, colaborando na manutenção da saúde. A atividade de lazer contribui para o aumento da qualidade de vida do ser humano. A prática do lazer é estimulada pelos governos, visto ter política trabalhista de férias remuneradas que permite ao trabalhador usufruir o benefício do lazer, porém nem todos tem conhecimento da finalidade de tal ajuda (Marcelino, 2002; Teixeira Júnior, Sferra \& Bottcher, 2012).

Os profissionais relatam ter informações suficientes para o exercício da profissional (95,2\%), porém o acesso a capacitação é reduzido. A capacitação dos farmacêuticos, muitas vezes, é vista como um problema para a gerência, porém a capacitação pode solucionar sérios problemas, promover melhorias na qualidade dos serviços ampliando a satisfação dos clientes. Cursos de capacitação podem fortalecer a humanização do trabalho, pois os profissionais podem tomar maior consciência da sua prática profissional e social (Belluzzo, 1995; Alves, 2004). 
Para promover a qualidade de vida no trabalho é importante que o gestor ouça os funcionários, compreenda o que os funcionários estão pensando, sentindo, querendo e, desta forma, possam utilizar ao máximo suas potencialidades, resultando em desenvolvimento para a empresa (Fernandes, 1996). A classe dos enfermeiros, por exemplo, tem discutido a qualidade de vida dos enfermeiros, tendo sido criado Comitê de Serviços Profissionais, bem como o Comitê do Conselho Internacional de Enfermagem (CIE), estão amplamente envolvidos nestas discussões. O CIE estuda o problema da saúde e da segurança no trabalho, sob o ponto de vista do enfermeiro e de sua equipe (Farias, Mauro \& Zeitoune, 2000; Silva, et al., 2006). Porém, na classe dos farmacêuticos não há nenhum órgão envolvido no acompanhamento da qualidade de vida laboral e da qualidade de vida e saúde dos farmacêuticos,

O presente instrumento adaptado neste estudo parece ser apropriado para avaliar a Qualidade de Vida dos profissionais farmacêuticos, bem como, rastrear os possíveis problemas que os mesmos vêm apresentando. Para o desenvolvimento destes estudos de qualidade de vida dos farmacêuticos é importante que os pesquisadores das Ciências Farmacêuticas realizam pesquisas nas diferentes áreas de atuação do farmacêutico. Também é importante ampliar o debate entre a classe sobre o impacto do exercício da profissão na saúde e qualidade de vida. Além disso, cursos de capacitação para os farmacêuticos, visando a identificação dos problemas que possam impactar na qualidade de vida e medidas de intervenção, são importantes.

Apesar deste instrumento fazer apenas uma triagem preliminar da visão do farmacêutico em relação a cinco dimensões, estes resultados não podem passar desapercebido, sendo importante uma investigação de sua causa. É muito importante que seja investigado se o farmacêutico apresenta a síndrome de Burnout, depressão ou outra patologia que possa impactar em sua visão relacionada o sentido da vida, a satisfação pessoal e demais aspectos.

\section{Conclusão}

Os resultados obtidos no presente estudo sugerem que este instrumento é adequado para a triagem de problemas nos cinco domínios. Uma vez obtidos os scores de cada domínio podem-se pensar em estratégias para a prevenção dos agravos à saúde, bem como o tratamento para estas patologias, é que, nas relações pessoais, nas condições de trabalho e ampliar o nível de independência. A análise global dos resultados pode sinalizar o nível de qualidade de vida de cada indivíduo.

Outra questão importante é que, apesar do número reduzido de entrevistados, pode-se sugerir que muitos os farmacêuticos estão adoecendo durante o exercício da profissão, sendo importante adotar medidas de intervenção. É importante que órgãos relacionados a classe elaborem políticas que visem prevenção e recuperação da saúde dos profissionais, bem como de promoção da qualidade de vida.

Em síntese, o método adotado no presente estudo possui algumas vantagens, tais como: não demanda muito tempo para responder, o estabelecimento de scores facilita a análise dos resultados, ainda serve para sinalizar o nível de qualidade de vida dos participantes, bem como analisar indícios de Burnout, problemas de relacionamentos e outras questões.

\section{Referências}

Abreu, W. C. (2001). Identidade, formação e trabalho: das culturas locais às estratégias identitárias dos enfermeiros. Formasau/Educa.

Alves, R. C. V. (2004). A gestão de pessoas em unidades de informação: a importância da capacitação no uso de tecnologias. Revista de Iniciação Científica da FFC, 4 (2), 32-51.

Aquino, T. A. A., Dara, D. M. B. \& Simeão, S. de S. S. (2016). Depressão, percepção ontológica do tempo e sentido da vida. Rev. bras. ter. cogn., 12(1), 3541. http://dx.doi.org/10.5935/1808-5687.20160006.

Assis, B. C. S. (2019). Satisfação e sobrecarga de trabalho entre profissionais de equipes da Atenção Primária à Saúde. Dissertação (Mestrado em Enfermagem) - Programa de Pós-Graduação em Enfermagem. Universidade Federal de Minas Gerais. 
Atos, E., Pires, D. E. P. de \& Campos, G. W. de S. (2009). Relações de trabalho em equipes interdisciplinares: contribuições para a constituição de novas formas de organização do trabalho em saúde. Rev. Bras. Enferm., 62(6),.863-869. http://dx.doi.org/10.1590/S0034-71672009000600010.

Baldoino, E. S. \& Santos, M. C. (2020). Qualidade de vida dos profissionais de enfermagem com dupla jornada de trabalho: uma revisão da literatura. Trabalho de conclusão de curso. Curso de Enfermagem da Escola de Ciências Sociais e da Saúde da Pontifícia Universidade Católica de Goiás, 48 p.

Barbosa, G. C. \& Buesso, T. S. (2019), O impacto da sobrecarga de trabalho e a satisfação do trabalhador em saúde mental. Revista Saúde, 45 (2), 1-13. $10.5902 / 2236583429678$

Batista, A. A. V., Vieira, M. J., Cardoso, N. C. dos S. \& Carvalho, G. R. P. de. (2005). Fatores de motivação e insatisfação no trabalho do enfermeiro. Rev. esc. enferm. USP, 39(1), 85-91. https://doi.org/10.1590/S0080-62342005000100011.

Belluzzo, R. C. B. (1995). Da capacitação de recursos humanos à gestão da qualidade em bibliotecas universitárias: paradigma teórico-prático para ambiente de serviço de referência e informação. Tese (Doutorado) - Escola de Comunicações e Artes, Universidade de São Paulo, 259 f.

Braverman, H. (1981). Trabalho e Capital Monopolista. (3a ed.), Zahar Ed.

Carlotto, M. S. (2010). A relação profissional-paciente e a síndrome de Burnout. Encontro - Revista de Psicologia, 12(17), 7-20.

Carvalho, C. G. \& Magalhães, S. R. (2011). Sindrome de burnout e suas consequências nos profissionais de enfermagem. Revista da Universidade Vale do Rio Verde, 9(1), 200-210.

Chambel, M. J. \& Santos, M. V. (2009). Práticas de conciliação e satisfação no trabalho: mediação da facilitação do trabalho na família. Estudos de Psicologia, 26(3), 275-286.

Eddleston, K. A. \& Powell, G. N. (2012). Nurturing entrepreneurs' work-family balance: A gendered perspective. Entrepreneurship Theory \& Practice, 36(3), 513-541. https://doi.org/10.1111/j.1540-6520.2012.00506.x.

Fabichak, C., Silva-Junior, J. S., Morrone, L. C. (2014). Síndrome de Burnout em médicos residentes e preditores organizacionais do trabalho. Rev Bras Med Trab., 12(2), 79-84.

Fagundes, E. deF., Costa, J. C. da \& Moreira, T. A. S. (2017). Qualidade de Vida no Trabalho: o caso dos agentes penitenciários em um Centro de Detenção Provisória do Rio Grande do Norte. Research, Society and Development, [S. l.], 5(2), 109-123. 10.17648/rsd-v5i2.101.

Farias, S. N. P., Mauro, M. Y. \& Zeitoune, R. C. G. (2000). Questões legais sobre a saúde do trabalhador de enfermagem. Rev. Enferm. UERJ, 8 (1), 26-32.

Fernandes, E. C. (1996). Qualidade de vida no trabalho: como medir para melhorar. Casa da Qualidade.

Ferreira, M. S. G. \& Anderson, M. I. P. (2020). Sobrecarga de trabalho e estresse. Revista Brasileira de Medicina de Família e Comunidade, 15(42), 21882188 .

Fleck, M. P. A. (2000). O instrumento de avaliação de qualidade de vida da Organização Mundial da Saúde (WHOQOL-100): características e perspectivas. Ciênc. saúde coletiva, 5(1), 33-38.

Frankl, V. E. (1989). Psicoterapia e sentido da vida. Quadrantes

Goméz, S. (2003). La incorporación de la mujer al mercado laboral: Implicaciones personales, familiares y profesionales, y me didas estructurales de conciliación trabajo-familia. Pamplona: Cátedra SEAT-IESE de Relaciones Laborales/ Universidad de Navarra.

Gonçalves, F., Fernandes, N., Setin, P. \& Calvo, E. (2013). Padronização de processos: estudo bibliográfico sobre sua aplicação, vantagens e desvantagens. ETIC- Encontro de Iniciação Científica, 9(9), 1-12.

Ishara, S. (2007). Equipes de saúde mental: avaliação da satisfação e do impacto do trabalho em hospitalização parcial. Tese (Doutorado em Saúde Mental), Universidade de São Paulo, Ribeirão Preto.

Johnson, S. J., O'Connor, E. M., Jacobs, S., Hassell, K. \& Ashcroft, D. M. (2014). The relationships among work stress, strain and self-reported errors in UK community pharmacy. Res Social Adm Pharm, 10(6), 885-895. 10.1016/j.sapharm.2013.12.003.

Junqueira, L. A. P. (1990). Gerência dos serviços de saúde. Cad. Saúde Pública, 6(3), 247-259. https://doi.org/10.1590/S0102-311X1990000300002.

Marcelino, N. C. (2002). Estudo do Lazer: uma introdução. Autores associados.

Maslow, A. (1968). Introdução à psicologia do ser. Eldorado.

Mattos, R. A. (1985). Desenvolvimento de Recursos Humanos e Mudança Organizacional, LTC/ANFUP, Gerência e Democracia nas Organizações. (2a ed.), Ed. Livre Ltda.

Moreira, A. P. F., Patrizzi, L. J., Accioly, M. F., Shimano, S. G. N. \& Walsh, I. A. P. (2016). Avaliação da qualidade de vida, sono e Síndrome de Burnout dos residentes de um programa de residência multiprofissional em saúde. Medicina, 49(5), 393-402. https://doi.org/10.11606/issn.2176-7262.v49i5p393-402.

Moreira, D. deS., Magnago, R. F., Sakae, T. M. \& Magajewski, F. R. L. (2009). Prevalência da síndrome de Burnout em trabalhadores de enfermagem de um hospital de grande porte da Região Sul do Brasil. Cad. Saúde Pública, 25(7), 1559-68. https://doi.org/10.1590/S0102-311X2009000700014.

Mott, D. A., Doucette, W. R., Gaither, C. A., Pedersen, C. A. \& Schommer, J. C. (2004). Pharmacists' attitudes toward worklife: results from a national survey of pharmacists. J Am Pharm Assoc., 44(3), 326-36. 10.1331/154434504323063968. 
Nauderer, T. M. \& Lima, M. A. D. daS. (2005). Imagem da enfermeira: revisão da literatura. Rev. Bras. Enferm., 58(1), 74-77. https://doi.org/10.1590/S003471672005000100014

Neves, T. S., Campos, L. de F. \& Morais, H. A. (2020). Qualidade de vida no trabalho dos servidores técnico-administrativos em educação em uma Universidade Federal de Minas Gerais. Research, Society and Development, [S. l.], 9(5), e1395220810.33448/rsd-v9i5.2208.

Nunes, L.(2003). Um olhar sobre o ombro: Enfermagem em Portugal (1881- 1998). Loures: Lusociencia. 375 p

Pavlakis, A., Raftopoulos, V. \& Mamas, T. (2010). Burnout syndrome in Cypriot physiotherapists: a national survey. Health Serv Res., 10 (63), 1-8.

Pêgo, F. P. L. \& Pêgo, D. R. (2016), Síndrome de Burnout. Rev Bras Med Trab., 14(2),171-6.

Pereira, A. S., Shitsuka, D. M., Pereira, F. J., \& Shitsuka, R. (2018). Metodologia da pesquisa científica. Santa Maria: UFSM, NTE. Recuperado de https://repositorio.ufsm.br/bitstream/handle/1/15824/Lic_Computacao_Metodologia-Pesquisa-Cientifica.pdf

Phipps, D. L., Malley, C. \& Ashcroft, D. M. (2012). Job characteristics and safety climate: The role of effort-reward and demand-control-support models. $J$ Occup Health Psychol., 17(3), 279-289. 10.1037/a0028675.

Piancastelli, C. H., Faria, H. P. de \& Silveira, M. R. da. (2000). O Trabalho em Equipe. Texto de Apoio da Unidade Didática I, Sequência de Atividades I, 4551 .

Ramos, C. I. C. F. (2018). Saúde sexual e envelhecimento: o papel dos fatores psicológicos e crenças sexuais. Dissertação, Mestrado Integrado de Psicologia, Faculdade de Psicologia e de Ciências da Educação da Universidade do Porto. 82p.

Rebouças, D., Legay, L. F. \& Abelha, L. (2007). Satisfação com o trabalho e impacto causado nos profissionais de serviço de saúde mental. Revista Saúde Pública, 41(2), 244-50. https://doi.org/10.1590/S0034-89102007000200011.

Ribeiro, J. M. daS. (2009). Autonomia profissional dos enfermeiros. Dissertação de Mestre em Ciências de Enfermagem, Instituto de Ciências Biomédicas de Abel Salazar, Universidade do Porto. 129p

Santana, C. S. \& Servo, M. L. S. (2019). Estresse no processo de trabalho dos profissionais de saúde: uma revisão de literatura. Anais Seminário de Iniciação Científica, 22.

Santos, V. L. C. G., Ferraz, A. F., Diogo, A. J. D. \& Souza, R. M. C. (1988). A imagem de enfermeira e do enfermeiro percebida por alunos ingressantes no curso de graduação. Rev Bras. Enferm., 41(3/4), 241-51.

Silva, B. M. da, Lima, F. R. F., Farias, F. S. deA. B. \& Campos, A. do C. S. (2006). Jornada de trabalho: fator que interfere na qualidade da assistência de enfermagem. Texto contexto - enferm., 15(3), 442-448. https://doi.org/10.1590/S0104-07072006000300008.

Souza, E. S. (2007). Um estudo sobre a repercussão do conflito trabalho-família e família-trabalho na satisfação no trabalho e na família e sua consequência na satisfação do hóspede: o caso da rede hoteleira de Porto de Galinhas. Dissertação de Mestrado. Mestrado em Administração - Centro de Pesquisa e PósGraduação em Administração. Faculdade de Boa Viagem. Recife.

Teixeira- Junior, M. A. B., Sferra, L. F. B. \& Bottcher, L. B. (2012). A importância do lazer para a qualidade de vida do trabalhador. Rev Conexão eletrônic., 581-95.

Teixeira, R. \& Nascimento, I. (2011). Conciliação trabalho-família: Contribuições de medidas adotadas por organizações portuguesas. Revista Brasileira de Orientação Profissional, 12(2), 215-225.

Tremblay, D-G. (2004). Desafio da conciliação entre trabalho e família nas empresas canadenses: Experiência sindical e gestão de recursos humanos. In Anais do Encontro Nacional Da Associação Nacional de Pós-Graduação Em Administração. Curitiba: ENAMPAD.

Vilela, E.C. S., Soares, L. R., Gusmão, A. S., Torres, R. A. T. \& Sá, E. C. (2015). Fatores de risco para estresse e transtornos mentais em farmacêuticos e auxiliares de farmácia. Saúde, Ética \& Justiça, 20(2), 77-83.

Wagner, L. R., Thofehrn, M. B., Amestoy, S. C., Porto, A. R. \& Arrieira, I. C. O. (2009) Relações interpessoais no trabalho: percepção de técnicos e auxiliares de enfermagem. Cogitare Enferm., 14(1), 107-13.

Waldow, V. R. (1999). Cuidado humano: o resgate necessário. (2a ed.), Sagra Luzzatto.

Young, C. E. F., Aguiar, C. F., \& Gema, E. P. (2013). Sinal fechado: custo econômico do tempo de deslocamento para o trabalho na região metropolitana do Rio de Janeiro. Revista Econômica, 2013 -1-17p. 